Acta Poetica $36 \cdot 2$

julio-diciembre

2015 (81-111)

\title{
Garcilaso y Cervantes en la perspectiva del canon
}

\author{
Pablo Gálvez y David Huerta
}

Este ensayo examina de modo sucinto la relación entre la obra de Miguel de Cervantes, en especial el Quijote, y la poesía de Garcilaso de la Vega en el horizonte de los valores consagrados en el canon literario de los Siglos de Oro. Para ello, primeramente se ofrece una breve semblanza biográfica e intelectual que busca establecer similitudes entre ambos autores; en segundo lugar, el texto registra diversas apariciones o "señales" garcilasianas en las páginas de la novela en sus dos partes (1605 y 1615) y las comenta con una visión al mismo tiempo crítica e histórica. El trabajo procura hacer una contribución sobre modos nuevos de analizar la tradición literaria y presta la mayor atención a las ideas cervantinas sobre la poesía.

PAlabras Clave: Garcilaso, Cervantes, poesía, Quijote, canon literario.

This essay examines in a succinct manner the relationship between the work of Miguel de Cervantes, especially the Quixote, and the verses of Garcilaso de la Vega in the context of the main values consecrated in the literary canon of the Spanish Golden Age. For that purpose, first we offer a brief biographical and intellectual note aiming to establish some similarities between both authors, and then we record different "signals" or quotations in the pages of both parts of the novel (1605 and 1615) and comment on them both from a historical and a critical viewpoint. This work tries to contribute on new ways of analyzing the literary tradition, paying the utmost attention to Cervantes' ideas regarding poetry.

KEYWORDS: Garcilaso, Cervantes, poetry, Quixote, literary canon.

Fecha de recepción: 26 de agosto de 2014

Fecha de aceptación: 20 de febrero de 2015 

Acta Poetica $36 \cdot 2$

julio-diciembre

2015 (81-111)

\author{
Pablo Gálvez y David Huerta \\ Universidad Nacional Autónoma de México \\ Facultad de Filosofia y Letras \\ esperantoenarameo@gmail.com \\ dhvm55@hotmail.com
}

\title{
Garcilaso y Cervantes en la perspectiva del canon
}

\section{Introducción}

Ante las vicisitudes y mutaciones del canon literario español, Francisco Rico hizo una penetrante reflexión en donde señala las justicias e iniquidades de la historia literaria, historia unida por una multitud de complejas razones al ejercicio de la crítica — si no es que dependiente o desprendida de aquélla- También es posible ver ese horizonte en forma invertida: la crítica como paridora de la historia literaria, con todo lo que de ello se deriva. Esa reflexión puede leerse en el párrafo inicial de las lúcidas páginas que Rico preparó como estudio preliminar para la reedición de una obra de crítica literaria moderna, sin duda ya clásica: La "Epístola moral a Fabio", de Andrés Fernández de Andrada, de Dámaso Alonso, publicada en 1978 y rescatada en 1993 en la Biblioteca Clásica de la editorial Crítica. He aquí lo que dice Francisco Rico:

Sobran los dedos de la mano para contar los poetas españoles cuya valoración se ha mantenido uniformemente en lo más alto a través de los siglos. La grandeza de San Juan de la Cruz es poco menos que un descubrimiento reciente; Góngora provocó siempre tantas iras cuantos fervores y se eclipsó durante doscientos años; la lírica fue pertinazmente 
considerada la parte menos valiosa de la producción de Quevedo... La ley del péndulo que tiraniza la historia de las artes apenas ha eximido de olvidos y desdenes las Coplas de Jorge Manrique, la obra de Garcilaso en bloque, ciertas odas de fray Luis de León... [las cursivas son nuestras] (en Alonso: IX).

Esa ley pendular dibuja los vaivenes de lo aceptable y lo rechazado por la doxografía literaria de épocas sucesivas. En el siglo XVI apenas hubo, en tono jocoserio, algunas reacciones de rechazo ante la auténtica revolución —o palingenesia - que significó en las letras de España la introducción del "itálico modo" llevada a cabo por Juan Boscán y Garcilaso, en una fecha tan exacta que no deja de causar asombro que fenómeno tan peculiar y radicalmente transformador tenga un preciso año inaugural: 1526. Quedan ahí para amenizar la tertulia con su evocación los versitos juguetones, apenas empañados por una leve sombra de casticismo y catolicismo ultramontanos, de Cristóbal de Castillejo:

\author{
Pues la sancta Inquisición \\ suele ser tan diligente \\ en castigar con razón \\ cualquier secta y opinión \\ levantada nuevamente, \\ resucítese Lucero, \\ a corregir en España \\ una tan nueva y extraña, \\ como aquella de Lutero \\ en las partes de Alemaña. \\ Bien se pueden castigar \\ a cuenta de anabaptistas, \\ pues por ley particular \\ se tornan a baptizar \\ y se llaman petrarquistas. \\ Han renegado la fee \\ de las trovas castellanas, \\ y tras las italïanas
}


se pierden diciendo que

son más ricas y loçanas

(Castillejos, citado por Rico en Alonso: 253-254).

El poema, "Reprensión contra los poetas españoles que escriben en verso italiano", sigue en ese tono, y las chanzas continúan hasta alcanzar un clímax paradójico: nada menos que un soneto donde se reiteran las acusaciones. Las consecuencias canónicas de lo que suele llamarse "revolución garcilasiana" son de largo alcance y marcan de manera imborrable el decurso entero de los llamados Siglos de Oro de la literatura española: significan un ensanchamiento definitivo y una sensible profundización de las posibilidades expresivas de la poesía en nuestra lengua. A ello no fue indiferente un hombre tan empapado de poesía, poeta él mismo, como Miguel de Cervantes.

En cuanto al canon al cual nos referimos en este trabajo, y para precisar la terminología, no es plenamente el académico ni totalmente el estético; es el "canon formado por los lectores y los editores en el proceso de recepción posterior de la obra", noción así descrita por Francisco Cuevas Cervera.

\section{Derroteros y devenires: los autores y su legado literario}

El destino de Garcilaso de la Vega y de su obra no pudo ser más paradójico. En el siglo XVI representaba lo contrario del casticisimo y el tradicionalismo: una renovación profunda y decisiva; en el siglo XVII simboliza lo contrario: el tradicionalismo casticista en cuya defensa salió nada menos que Lope de Vega - en ese momento la renovación profunda y decisiva la constituye la poesía de Luis de Góngora. Léase el soneto "A la nueva lengua" (Rivers: 265), en el que el Fénix resucita a Garcilaso y a Juan Boscán, cuyo primer cuarteto dice así:

—Boscán, tarde llegamos. ¿Hay posada?

- Llamad desde la posta, Garcilaso.

— ¿Quién es? —Dos caballeros del Parnaso.

—No hay dónde nocturnar palestra armada. 
Incluido en el Laurel de Apolo (1630), es un poema burlesco escrito "contra la nueva lengua poética", como lo rotulan los editores de los versos lopescos. La nueva lengua poética era entonces (siglo XVI) la de Garcilaso; la nueva-nueva lengua poética fue un siglo más tarde (XVII) la de Luis de Góngora. Los enemigos de esas transformaciones se llaman respectivamente Cristóbal de Castillejo y Lope de Vega. Esto da para ponerse a pensar en el destino de las obras poéticas, aun en aquellas que se han salvado de "olvidos y desdenes" (F. Rico, en el pasaje citado), pero no de malos entendidos.

El maestro Dámaso Alonso ilustró la profunda impresión que produjo la poesía de Garcilaso de la Vega en el siglo XVI con un símil interesantísimo: a la generación de Alonso - la celebérrima, y gongorina por añadidura, de 1927 - la poesía de Rubén Darío les hizo un efecto similar, según su noticia de protagonista y testigo. Garcilaso, Darío: el poeta toledano y el poeta de la nicaragüense Metapa, hermanados a través de los siglos y los mares en la grandeza poética y en la influencia de sus respectivas obras. La recepción de Garcilaso fue de intensidad notable, entonces. Los lectores del cinquecento no fueron insensibles a ella en modo alguno: todos, prácticamente todos, fueron garcilasianos.

Nacido en 1547 - el mismo año en que murió el conquistador de México, Hernán Cortés-, Miguel de Cervantes creció en la España imperial de los primeros Austrias. Garcilaso había sido contino del emperador Carlos, el césar cristiano; soldado, viajero, músico, humanista, poeta y además buen amigo de sus amigos y hombre enamoradizo y no poco trágico - hasta su muerte en la Provenza, consecuencia de su deseo de impresionar o agradar a Carlos $\mathrm{V}$-, el gran toledano está en la cúspide o en el centro de una forma de la idealidad española o europea que no pudo menos que seducir a Cervantes. Él mismo era soldado, y en su hoja de servicios figuraba la fecha gloriosa de la Batalla de Lepanto, en la que según todos los testimonios el joven alcalaíno de 24 años se comportó con innegable bravura. Esto es parte del autorretrato de Cervantes en el prólogo de las Novelas ejemplares:

Fue soldado muchos años, y cinco y medio cautivo, donde aprendió a tener paciencia en las adversidades. Perdió en la batalla naval de Lepanto la mano izquierda de un arcabuzazo, herida que, aunque parece fea, él la 
tiene por hermosa, por haberla cobrado en la más memorable y alta ocasión que vieron los pasados siglos ni esperan ver los venideros, militando debajo de las vencedoras banderas del hijo del rayo de la guerra, Carlo Quinto, de felice memoria (77-78).

\section{El pensamiento garcilasiano}

El apego al poeta de Toledo constituyó una parte sustancial de la obra y el pensamiento de Cervantes —no nada más una parte de su mentalidad literaria, sino también de su andadura vital—. Algo había en ese poeta del siglo Xvi de los elementos morales, intelectuales y de conducta del perfecto caballero, tal y como fue codificado en El cortesano, libro de Baldassare Castiglione traducido por Juan Boscán y revisado por Garcilaso de la Vega; algo había en Cervantes, asimismo, del europeísmo garcilasiano puesto de relieve por Azorín en un precioso artículo titulado simplemente "Garcilaso" (33-39). Ese "algo" multiforme y cambiante, pero sellado siempre por la altura espiritual y estética, fue una suerte de estrella polar para Cervantes. ${ }^{1}$

El particularísimo pensamiento de Garcilaso fue disonante con el de sus contemporáneos, y único en su tiempo y latitudes. Azorín puntualiza tres aspectos que llaman marcadamente la atención al leer, aún ahora, al toledano, más todavía si consideramos lo poco común que resultó esa poesía en su contexto original. El crítico señala en primer término el "europeísmo" como rasgo fundamental en el quehacer garcilasiano; esto es, mientras el resto de sus colegas versificadores se limitaban a plasmar con lujo de lugares comunes el paisaje español — celosamente apegados al realismo, por otra parte-, aquél aspiró siempre a ofrecer un panorama menos localista, donde figurasen, por ejemplo, Alemania y Francia (y no sólo eso: además “con dos palabras, nos da la psicología de los

1 "Bien conocida es la fortuna de Garcilaso en los siglos XVI y XVII [...] pero nadie ha puesto su atención en el extraordinario fervor con que Cervantes leyó la obra del divino toledano, una de sus mejores admiraciones. No fue un entusiasmo juvenil y pasajero, sino todo lo contrario. El eco de las lecturas garcilasistas resuena por toda la obra cervantina, desde la elegía a la muerte de Isabel de Valois hasta el Persiles, pasando por el Quijote y las Comedias", apunta José Manuel Blecua en su ensayo "Garcilaso y Cervantes" (1947). 
más poderosos pueblos europeos", Azorín: 36); apostó pues por tendencias mucho más cosmopolitas que las vigentes en su época y entorno.

En segundo lugar, y esto acaso sea el atributo más eximio y rupturista con los "intonsos poetas de su edad", en toda la obra de Garcilaso no advertimos el menor cariz de religiosidad: "De todos los poetas españoles de los siglos XVI y XVII, Garcilaso es el único que no haya escrito ni un solo verso de asunto religioso [...] no se puede citar ni un verso ni un epíteto religiosos" (37). Esto es significativo en un momento sociopolítico e histórico-cultural donde el teocentrismo ejercía plenamente su exacerbado rigor en materia artística y científica. La época de Garcilaso aún padeció el dogmatismo inquisitorial y su inhumano yugo; apenas en los días de Cervantes algún atisbo mínimo de libre pensamiento se dejó traslucir para las mentes creadoras e investigadoras, y aun así la influencia de la Contrarreforma impedía un verdadero renacimiento: el modus vivendi seguía convulso entre el oscurantismo y la ilustración redentora.

Así las cosas, llama enormemente la atención que el laicismo de que hizo gala nuestro poeta haya sido tan bien asimilado por todos, especialmente por los mojigatos, censores y fanáticos. Y esta admiración se acentúa más, si cabe, al ponderar el tercer rasgo que Azorín destaca como particular y privativo de la poética garcilasiana, pues tiene resonancia en los dos previos: nos dice el crítico que los paisajes con que el poeta adereza sobre todo la Égloga III se distinguen por elementos fantásticos y no del todo realistas; ${ }^{2}$ esto es, por ejemplo, la aparición de las ninfas (que por principio de cuentas viven en el fondo del Tajo), quienes bordan ricamente en "unas sutiles telas [...] pinturas de mitología, de amores y de leyenda" (39).

${ }^{2}$ Citamos para aludir al sentido concreto a que remite Azorín: "Garcilaso no se limita a copiar el paisaje directa y realísticamente. En la naturaleza pintada por Garcilaso hay ya un elemento que va a hacer desviar, durante dos o tres siglos, el sentimiento español del paisaje, del campo, de la vida rústica. [...] En Garcilaso un ambiente de refinamiento y humanidad envuelve a la naturaleza. Hay algo en Garcilaso que nos hace sentir ciertos artificios mitológico-galantes de tiempos posteriores; [...] Pinta un paisaje de Toledo [en la Égloga III] (espesura amena, tupida, junto al Tajo); pero sobre el paisaje castellano se destaca el grupo grácil y sensual de tres o cuatro ninfas. [...] ¿Existirá alguna correspondencia lógica entre la índole del paisaje toledano y la superposición de que le hace objeto Garcilaso? Ninguna" (37-39). 


\section{El pensamiento cervantino}

Ahora, para establecer una consonancia entre el talante intelectual y sensible de ambos genios pondremos sobre la mesa algunos paradigmas estéticos e incluso filosóficos a los que se apegó el mal llamado "manco de Lepanto" en su quehacer literario. Al mismo tiempo, esto dará cuenta de la preceptiva crítica innata, apegada con todo rigor a las formas canónicas, y por otro lado de su agudo sentido de originalidad, un instinto creador que desbordaba los parámetros y lineamientos establecidos. ${ }^{3}$ $\mathrm{Y}$ desde luego, tal antagonismo inmanente y esas posturas encontradas entre la fidelidad a las normas de la poética clásica y sus naturales tendencias innovadoras suscitaron a lo largo de los años y las lecturas opiniones que sólo suscriben la complejidad de la mente cervantina.

Reparemos ahora en la polémica alrededor del libro Cervantes reaccionario (1924), del crítico italiano Cesare de Lollis ("la mayor desdicha de la crítica cervantina"), ${ }^{4}$ a quien el genial alcalaíno padrastro de don Quijote le merecía sólo opiniones desdeñosas y en su interpretación fue nada más que - parafraseamos - un hombre semiinculto, de gran pobreza intelectual, que sólo se dedicaba a contar por contar ("aunque lo haga con superlativo acierto", Márquez Villanueva); esto avivó el desacuerdo de uno de los más grandes entendidos en la cuestión cervantista, Américo Castro. Al año siguiente, a guisa de magistral réplica y apología o mera reivindicación, Castro lanzó El pensamiento de Cervantes (1925), estudio con el cual

teníamos ahora, en cambio, un paso brusco, sorprendente a la autoría de Cervantes [que lo ponderaba] como un hombre de saberes a la altura de los más granados de su tiempo [...] situado Cervantes en la avanzadilla donde el humanismo empezaba a transformarse en modernidad, y entonces

${ }^{3}$ El gran cervantista inglés E. C. Riley aborda esta dualidad liberal/conservadora con sumo detenimiento y buen tino en los primeros capítulos de su Teoría de la novela en Cervantes. Volveremos a este punto más adelante.

${ }^{4}$ Formulación con la que arranca la conferencia de Francisco Márquez Villanueva, "La cultura del Cervantes pensador", dictada el 22 de octubre de 1998 para la Fundación Juan March. Audio disponible - y ampliamente recomendable - para su disfrute íntegro en el enlace virtual: <http://www.march.es/conferencias/anteriores/voz. aspx?id $=796>$. 
la comprensión profunda de sus páginas les requería un ejercicio hermenéutico [...] un continuo barajar de nombres como son los de Lorenzo Valla, Telesio, Montaigne y Erasmo. Al otro extremo de reaccionario, Cervantes aparecía, por el contrario, rebosante de incitaciones atrevidas en el terreno [...] de una moral extra-cristiana y naturalista, de una religiosidad espiritualizada al margen de la Contrarreforma y sobre todo [...] un espíritu universalmente crítico, exento de ningún lastre de vulgaridad (Márquez Villanueva).

Y añade brillantemente Márquez Villanueva:

Cervantes respondía con esto [su erasmismo] a estímulos igualmente perceptibles en otros ingenios inquietos de sus años formativos [...] cuando ya el programa literario español tendía a teñirse de conformismos bajo las alas de un fenómeno barroco, Cervantes venía de un puro humanismo garcilasiano, gustaba de pisar sobre seguro y no sentía la menor prisa en sumarse a lo que a comienzos del siglo XVII debían de parecerle modas exageradas y pasajeras en el terreno de la literatura (las cursivas son nuestras).

En el citado texto, Castro analiza y pondera los rasgos, accidentes y altibajos que dieron forma al espíritu cervantesco. En el hilo de los razonamientos de Castro se enhebran los contextos vitales del "ingenio lego" —-fórmula acuñada por el erudito del siglo XVII Nicolás Antonio-; de la mano de sus circunstancias, Cervantes se vio ceñido por su entorno (local, español) y gracias a éste y a las influencias extranjeras (italianas y grecolatinas, la mayoría) pudo configurar sus ideas y su obra. El canon de la época se había moldeado entre el oscurantismo medieval y el pujante espíritu renacentista impregnado de ideas transformadoras, ricas en doctrinas antidogmáticas como el humanismo y el naturalismo. Empezaban a respirarse nuevos aires,

mas otro grave peligro amenazaba a la literatura idealista [...] el arte en el siglo XVI iba derechamente a crear una zona autónoma en que los espíritus no tenían más estímulos que los puramente terrenos y humanos. La literatura hacía verdadera competencia a la religión [...] El concilio de Trento vigilará enérgicamente la literatura: "Libri qui res lascivas sed obscoenas ex professo tractant, narrant aut docent". Desde luego, el 
concepto de lo lascivo era bastante más amplio para los padres y moralistas del que hoy tendríamos [...] las declamaciones contra las ingenuas novelas pastoriles, en las que los confesores veían toda clase de peligros para la honestidad de las doncellas. A lo que se aspiraba era a poner trabas al cultivo de la sensibilidad y fantasías puramente mundanas. Ése es el sentido de las censuras de los libros de caballerías que tomaron incremento durante la "Contrarreforma". Pónese entonces de moda volver a lo divino a las obras profanas, y no sólo los libros de caballerías, mas también autores de [tan sublimada idealidad] (sic) como Boscán y Garcilaso (Castro: 49-51).

Los razonamientos naturalistas, grosso modo, postulan que si Dios se encuentra presente en todas las cosas, entonces obviamente su esencia es inmanente a la naturaleza; a todas luces, esto sonaba a blasfemia para la Iglesia; la vuelta a lo divino de la poesía garcilasiana hecha por Sebastián de Córdoba, Las obras de Boscán y Garcilaso, trasladadas en materias cristianas y religiosas, Granada, 1575 (citado por Castro: 49-51) ilustra esas exigencias de la cultura cristiana. Las nuevas formas de pensamiento fueron prontamente asimiladas por los poetas e incorporadas en sus obras. Américo Castro nos dice: "Tales son las bases ideológicas de la doctrina naturalista que en varia forma refleja la literatura. Mucho antes de Cervantes había dicho Garcilaso: 'Una obra sola quiso la natura / hacer como ésta, y rompió luego apriesa / la estampa do fue hecha tal figura"" (159-160); sin embargo, este tópico no proviene tampoco de la originalidad del poeta toledano, sino que tiene un sustrato acaso italiano, pues como a continuación observa Castro, es un "pensamiento tomado, según creo, del Ariosto: 'Natura il fece, e poi ruppe la stampa'. Cervantes, siguiéndolos, desarrolla más la idea: Robó la naturaleza / lo mejor de cada cosa / para formar esta pieza, / y así la sacó hermosa" (159-160). ${ }^{5}$

El mismo concepto aparece en forma distinta: "Yo he oído decir — habla Sancho - que esto que llaman naturaleza es como un alcaller

${ }^{5}$ Cabe señalar que la cita en italiano de Ariosto corresponde al Orlando furioso (X, octava 84). En este mismo sentido, los versos de La gran sultana que Castro registra, pero que pasó por alto anotar, pertenecen a la Jornada primera, vv. 361-364. 
que hace vasos de barro, y el que hace un vaso hermoso también puede hacer dos y tres y ciento" (II, 30).

El rigor inflexible del clero censor se hizo sentir en Cervantes; no obstante, el novelista supo eludir las limitaciones impuestas por la hegemonía eclesiástica. Si bien - y es de capital importancia tener bien presente esto- Cervantes siempre profesó una devoción de cristiano viejo, su fe no le impedía abrirse a nuevas prácticas de pensamiento para expandir así las propuestas y, alcances de su obra. "Lo que venía de Italia es, ni más ni menos, el primer gran canon poético del Siglo de Oro, aquí representado por Garcilaso: una revolución en la métrica y en la sensibilidad. T. S. Elliot ya nos advierte que 'una forma métrica distinta es un modo diferente de pensar', y sobre todo, de sentir" (Carreira: 196). ${ }^{6}$ Ante la instauración de la nueva pauta artística, los reajustes no se hicieron esperar; nadie quería quedar fuera de la innovación. Sin embargo, más allá de su humanismo y su naturalismo, Cervantes permanecía fiel — como quedó asentado líneas arriba con la cita de Márquez Villanueva - a su poética bucólico/garcilasiana. Castro lo puntualiza inmejorablemente:

Todos hemos creído que en la España del siglo XVI no hubo alta cultura del espíritu, sino arte piadoso o de fantasía. [...] Cervantes [...] no obedecía meramente a su espíritu compasivo y cristiano, sino a estar imbuido de ideología renacentista [...] sus ideas serían cualquier cosa, a lo sumo vulgares y corrientes: "no había tenido tiempo ni afición para formarse otras", como perentoriamente decidió Menéndez Pelayo. Decían que razonaba mal, y además le achacan renuncios, olvidos y contradicciones en que nunca incurrió. [...] Los hombres serios y de estudio sostenían que en Cervantes no había sino fantasía y humorismo, a lo sumo un espíritu jovial, satírico y mordaz, heredado de los erasmistas. Pero aconteció que al leer a Cervantes se notaba algo, no se sabía qué [...] la poderosa unidad de la concepción ideal de Cervantes, la armonía y concordancia de sus partes. Las bases de sus caracteres literarios son quintaesencia del naturalismo y estoicismo de su siglo. [...] Cervantes se nos muestra

6 "T. S. Elliot, Criticar al crítico y otros escritos, trad. de Manuel Rivas Corral, Madrid: Alianza, 1967, 170. La observación es valiosa aunque peca algo de optimista" [Esta nota al pie también forma parte del texto citado de Antonio Carreira (196)]. 
plenamente como una de las más espléndidas floraciones del humanismo renacentista (337-340).

Apenas en la última década de su vida, tras el éxito y la buena acogida que tuvo la Primera parte del Quijote, Cervantes pudo finalmente saborear un poco las delicias de la fama y la gloria; fue una semiconsagración como autor del gusto de las masas (como su archirrival Lope de Vega); es difícil precisar si por ello entró en ese momento en el canon, aun cuando nos inclinaríamos a afirmarlo: fue un autor leído, recomendado y, quizá lo más importante, un escritor cuya obra fue conocida y reconocida más allá de las fronteras españolas. No es exagerado decir lo siguiente: a raíz de la obra cervantina se impuso una completa reconfiguración del canon literario español. Llegó incluso a declarar que su Quijote se ganaría el lugar privilegiado del que hoy goza dentro del quehacer literario ("Y así debe de ser de mi historia, que tendrá necesidad de comento para entenderla", asevera el propio don Quijote en Cervantes 2004, II, 3: 571) y artístico ("Yo apostaré — dijo Sancho — que antes de mucho tiempo no ha de haber bodegón, venta ni mesón o tienda de barbero donde no ande pintada la historia de nuestras hazañas", II, 71: 1087).

\section{La autocrítica cervantina: lucidez, conciencia e ironía}

La pasión poética de Cervantes tiene un trasfondo garcilasiano. El genial novelista siempre se consideró poeta, y su esfuerzo está abonado por la auténtica riada de versos que compuso a lo largo de su ajetreada vida. Cervantes como versificador: un falso problema, además, que el cervantismo ha despachado afirmando sin matices que "era mal poeta". Todo tiene su origen en una mala lectura, que a continuación comentamos.

Una y otra vez los versos iniciales del Viaje del Parnaso (1614) han sido mal leídos y peor interpretados. Repasemos el terceto malhadado:

Yo, que siempre trabajo y me desvelo

por parecer que tengo de poeta

la gracia que no quiso darme el cielo

(capítulo I, vv. 25-27). 
Los cervantólgos, en su inmensa mayoría, se han propuesto no comprender lo que hay aquí. Tiene un nombre en la antigua retórica: captatio benevolentice, o falsa modestia en el lenguaje común. Con esas palabras Cervantes no se propone otra cosa que granjearse la simpatía del auditorio, de los lectores, de quienes asisten en la forma que fuere a la noticia sobre su viaje heroico a defender, al lado del dios Apolo, a los buenos poetas contra el ataque de los malos, dispuestos a tomar por asalto el Monte Parnaso, hogar de las Musas y origen venerable de toda poesía, de todo arte verdadero, de todo valor estético. La verdadera opinión de Cervantes sobre sí mismo como poeta —o por lo menos el apuntamiento que hace para revelar su innegable pasión poética - está un poco más adelante, cuando el dios Mercurio, enviado por Apolo, se presenta ante él y dice estas palabras:

¡Oh Adán de los poetas, oh Cervantes! (1973: 53)

¿Qué juicio es más "sincero", más revelador de la opinión de Cervantes acerca de su propia poesía? ¿El de la "falta de gracia" o el de la primacía y principalidad de sus versos (eso significa ser el "Adán de los poetas", ni más ni menos)? Lo primero lo dice el propio Cervantes en el principio mismo del Viaje del Parnaso, conforme va preparando la aventura fabulosa en los reinos de la poesía; lo segundo lo dice el dios Mercurio. Debe tenerse en cuenta que al lado de la noble misión del personaje como "mensajero de los dioses", Mercurio es también la divinidad que preside los chismes, los decires, los pareceres de la gente común: Cervantes sería el "Adán de los poetas" en la opinión de una comunidad hipotética cuyo conducto es Mercurio. Lo cierto es que no era ésa la opinión acerca de Cervantes, por lo menos en la comunidad que él mismo tenía más cerca: la comunidad literaria, los cenáculos de los escritores. Estamos ante un ejemplo diáfano, pues, para quien desee verlo, de la socarronería cervantina: soy modesto, como se puede ver; si alcanzo alguna alabanza por mis versos, es otro quien la formula. $\mathrm{La}$ modestia está presente con plenitud en los tres versos de la captatio benevolentice; la alabanza está en otra boca, no en la mía - aunque esa boca sea la de un dios. 
Recordemos que según Márquez Villanueva, "el Viaje del Parnaso [constituye para Cervantes] poner sus cartas boca arriba" en cuanto a la materia poética se refiere. La astucia del alcalaíno no iba a la zaga de su talento y demás dones, otorgados por el cielo o por otra merced cualquiera; sus argucias radicaban, entre otras cosas, en movimientos tan inteligentes como anticiparse a sus detractores, tal como dice Riley: "El arte característico y original de Cervantes empieza con un acto de distanciamiento de sí mismo y de su obra [...] Una y otra vez, Cervantes tiene la precaución de desarmar a sus posibles críticos siendo él el primero en criticarse" (54-55).

Asimismo, e increíblemente, desde el título de su obra más insigne ha habido malas interpretaciones de la escritura cervantina; ahí está la palabra ingenioso, por ejemplo, con la cual Cervantes califica a su caballero/hidalgo. Las lecturas van desde lo superficial y perogrullesco, atribuyendo al apelativo la carga semántica obvia (y más bien moderna) con los sinónimos "ocurrente", "perspicaz", "astuto" e incluso (en función de la época y la obra en sí) "gracioso", "discreto" y "hábil con las palabras". Una de las lecturas más coherentes propone que el adjetivo, en resonancia ariostesca, valdría por "loco" (ésta es también la sema o intención original con que el poeta italiano trata a su Orlando: el furioso del título quiere decir justamente eso: "loco, demente"). Si atendemos a otra evidencia bibliográfica sacada a la luz una vez más en esa magistral conferencia de Francisco Márquez Villanueva, tenemos que además de Ariosto, otra influencia matiza el problemático sema:

El título [...] ¿qué quiere decir realmente esto de "ingenioso"? [...] se tardó mucho en comprender que se trataba de una terminología especial, [...] médica o mejor dicho psiquiátrica, [...] con el valor de "enfermo de la imaginación" tal como lo introducía el médico navarro [...] Juan Huarte de San Juan en su Examen de ingenios para las ciencias, de 1575. Este libro es [...] la obra cumbre de un pensamiento médico [...] sobre base de formación fisicista y al margen del desarrollo escolástico del momento (Márquez Villanueva).

No fue Huarte el único autor que en esta materia significó una influencia insólita - por venir de un ámbito no-literario - para Cervantes: leyó también La nueva filosofía de la naturaleza del hombre (1587), 
libro en ruptura total con la tradición galeno-hipocrática que se publicó originalmente atribuido a una mujer, una tal "doña Oliva Sabuco de Nantes; pero no, no era una mujer, era el seudónimo de su padre, el bachiller Miguel Sabuco y Álvarez" (Márquez Villanueva). El espíritu cervantino fue tan claro y lúcido que pudo conciliar arte y ciencia ${ }^{7}$ bajo un nuevo enfoque, incluso filosófico.

\section{Las señales garcilasianas}

Buscar - y encontrar, con absoluta seguridad - las citas, glosas, recreaciones garcilasianas en el Quijote, por ejemplo, es una tarea relativamente fácil y poco prometedora: es evidente el apego de Cervantes a la poesía de Garcilaso de la Vega. Hay que hacer esa tarea con una mira clara: ilustrar los accidentes del canon. ¿Qué mejor manera de hacerlo que acercarse al punto de contacto entre dos autores canónicos, como Cervantes y Garcilaso, para tratar de entender el sentido y los alcances de su relación, en la perspectiva misma del canon?

La admiración de Cervantes por Garcilaso - una admiración en acto, por así decirlo: se expresa en las páginas de ese lector excepcional que fue el "ingenio lego" más célebre de la literatura universal - constituye un rico venero de ideas que debemos discernir en los textos si queremos comprender la relación entre ambos autores. Llamamos "señales garcilasianas" a todo tipo de huellas en forma de glosas, citas directas, recreaciones, diversas formas de imitatio, alusiones y aun expresión de ideas o acuñación de imágenes en las cuales puede incluso no ser reconocible a primera lectura y con absoluta claridad el origen en los versos del poeta toledano. Los expertos suelen buscar, a veces con descuido, esas huellas en las páginas cervantinas. Sirva de ejemplo la noticia que damos a continuación:

${ }^{7}$ No obstante, la diferenciación entre ambas era poco clara por entonces: "Durante la Edad Media y hasta mucho después del Renacimiento, la distinción entre ars y scientia fue algo muy confuso. Tradicionalmente, los poetas provenzales, [...] españoles [...] como el Marqués de Santillana y [...] posteriores, incluido Cervantes, denominaron 'ciencia' a la poesía” (Riley: 35). 
Jorge Aladro-Font y Ricardo Ramos Tremolada afirman en su estudio "Ausencia y presencia de Garcilaso en el Quijote" (1996), con toda contundencia, que en la Primera parte de la novela cervantina "la presencia de Garcilaso se reduciría prácticamente a tres reminiscencias"; el poeta toledano, dicen, "pasa casi desapercibido" en esas páginas. En la "Canción de Grisóstomo" (capítulo XIV), estos estudiosos señalan una cita directa de la Égloga II (verso 606), pero no la consideran propiamente lo que llaman "reminiscencias", que según ellos son las siguientes: Canción IV (capítulo XI), Égloga II (también en el capítulo XI) y Égloga II una vez más (capítulo L). Nosotros hemos localizado, solamente en la Primera parte, por lo menos dieciséis huellas, glosas, citas y reminiscencias garcilasianas, que preferimos llamar "señales" por efectos de concisión y encuadre semántico, ya que nuestro propósito es rastrearlas en ambas partes del Qujiote $^{8}$ - y preferimos, por ende, darles esa nomenclatura y no la de "huella", por ejemplo- así como discernir su importancia en la configuración total de la obra. Para ello hemos echado mano de las ediciones más solventes, en tiempos modernos, de las obras del poeta toledano y el novelista alcalaíno (véase la bibliografía). Establecido esto, podemos empezar.

Una de las primeras señales garcilasianas (pues pueden apreciarse estilemas ya desde el prólogo) está en el verso 14 del soneto prologal del Quijote, "Del Caballero del Febo a Don Quijote de la Mancha". El terceto conclusivo dice así:

Mas voz, godo Quijote, ilustre y claro,
por Dulcinea sois al mundo eterno,
y ella, por vos, famosa, honesta y sabia.

8 No buscamos ser exhaustivos en este punto, sino sólo aludir a algunas de las señales que ponderamos cruciales en la conformación del texto en cuanto obra literaria instalada (y luego encumbrada) en el marco canónico de una tradición precedente; nos detendremos a analizar apenas un par de aspectos aislados de las señales pertinentes. No obstante, para una localización pormenorizada de las señales garcilasianas que hallamos en el libro véase el "apeíndice" (creemos que huelga aclararlo, pero para que no pase por errata, el vocablo es la conjunción de apéndice e índice) al final del ensayo. 
El verso "y ella, por vos, famosa, honesta y sabia", con la enumeración de tres virtudes, proviene con seguridad del verso 1418 de la Égloga II de Garcilaso: "dulce, pura, hermosa, sabia, honesta"; este pasaje de cinco palabras encomiásticas para la mujer colmada de virtudes, dechado de esposa aristocrática, forma parte de un epitalamio: es un elogio de doña María Enríquez, cónyuge de don Fernando Álvarez de Toledo, tercer duque de Alba, casa noble ligada por diversos motivos al poeta toledano. Garcilaso enlista cinco virtudes; el Caballero del Febo sólo tres, pero se trata de la misma hechura retórica dentro del marco endecasilábico. Una crítica citada en la edición del Quijote de 1998, Adrienne Laskier Martín, "ve en famosa, honesta y sabia una alusión sarcástica a Micaela de Luján (Lucinda), la amante adúltera y analfabeta de Lope de Vega" (260).

Las enumeraciones son, entonces, así: "dulce, pura, hermosa, sabia, honesta" en Garcilaso; "famosa, honesta y sabia" en Cervantes. "Famosa" no está en Garcilaso; pero se halla en serie de densidad semántica y axiológica con las demás cualidades. "Sabia" y "honesta" están ordenadas de forma diferente: "sabia, honesta" en Garcilaso, "honesta y sabia" en Cervantes. La atribución de sabiduría a Dulcinea, casi sobra decirlo, pone de relieve la ironía del soneto.

En su conferencia acerca de "La cultura del Cervantes pensador", Francisco Márquez Villanueva habla del autor alcalaíno como heredero de lo que llama "humanismo garcilasiano" (véase El pensamiento cervantino en este ensayo); la frase puede sonar extraña, pues no acostumbramos poner a un poeta en la nómina de "los humanistas", como Erasmo de Rotterdam, Alonso de Valdés o Juan Luis Vives. Pero en la medida en que el poeta toledano fue un genio de las letras humanas, de acuerdo con el eje de las humanidades renacentistas, cabe hablar sin desdoro de ese tipo de humanismo, del cual Miguel de Cervantes es heredero directo, en especial a través de su tratamiento de la materia poética.

La localización de las señales garcilasianas no es, en sí misma, tarea de muchos alcances, como hemos dicho. Puede llegar a tenerlos si la enmarcamos en los trabajos sobre la historia intelectual de la literatura de nuestra lengua, como pedía Márquez Villanueva. La obra de este crítico español ha sido una de nuestras principales guías en la composición de este ensayo cervantino-garcilasiano. 


\section{La relación de los autores}

No hay la menor duda sobre el garcilasismo de Miguel de Cervantes; es uno de los rasgos principales de lo que podríamos llamar su "pensamiento literario" - podemos llamarlo así, claro, desde 1925, año de aparición del ya citado libro clásico de Américo Castro-. En las páginas de la obra de Cervantes brilla o se disimula astutamente la presencia del poeta toledano, de sus versos, de su genio verbal. Ese garcilasismo cervantesco es una especie de invitación implícita para los lectores que quieran tratar de comprenderlo como un signo vivo, a la manera de una presencia textual, o como un trasfondo espiritual o artístico; significa, por lo tanto, un motivo de reflexión y estudio, de crítica y de análisis: una suerte de objeto fascinante y fecundo. El norte último de nuestro ensayo, entonces, es hallar la esencia poética, sustrato o aliento vital que configura en gran medida el ethos quijotesco (y por ende, es decir por antonomasia, el del propio autor). No fueron los libros de caballería los que estragaron los sesos del hidalgo; en todo caso, no únicamente fueron las aventuras de Amadís, Tirante el Blanco y Palmerín, sino que la actitud frente a los últimos años de su vida del otrora Alonso Quijano - al final de su periplo, "el Bueno"- obedece a una necesidad mucho menos "prosaica" y está impregnada por los versos encumbrados de la más rica poesía de la Península Ibérica en su tiempo.

Los descalabros que sufre el ilustre manchego, si bien se ciñen preponderantemente a la preceptiva de la andante caballería, conllevan en su obrar un remanente poético a primera vista - lectura, más bieninextricable, mas las aristas que subyacen en todas las empresas y aventuras de nuestro caballero apuntan a una intención irreductible: poner en práctica el quehacer poético por vía del ejercicio del olvidado arte de Lanzarote; encarnar en él mismo, así como en la idílica concepción de Dulcinea del Toboso, lo que para él constituía la Poesía, "ciencia [...] que encierra en sí todas o las más del mundo" (II, 18: 682; véase la nota 7 de este trabajo).

La vena heroica es la que don Quijote más se preocupa en cultivar; sin embargo, recordemos que como bien acota Unamuno, "el verdadero héroe es sépanlo o no, poeta, porque, ¿qué sino poesía es el heroísmo?" (citado por Riley: 65). Si atendemos a este razonamiento $-\mathrm{y}$ le añadi- 
mos un poco de nuestra cosecha- podríamos, pues, establecer que la fuerza que alienta al caballero se debe por entero a Dulcinea, y advertimos entonces que ésta es trasunto de un mero ideal poético, pleno de quimeras platónicas. Es decir: el ánima de don Quijote rebosa lirismo; su arma más poderosa radica en las ensoñaciones, muchas de ellas garcilasianas. Aventuremos entonces esta idea: las figuras de Sancho y de su amo están provistas cada cual de un cariz reflejado en su léxico (el modo de hablar de los personajes reviste y denota la luz de su entendimiento y lo errático de su conducta): en tanto que uno, el escudero, no cesa de intercalar refranes, "vengan o no a pelo", el otro cita y trae a colación versos y pasajes de gran riqueza lírica; aquél utiliza la proverbial sabiduría popular a guisa de escudo para defenderse del incesante y hostil embate de que es presa a lo largo de la historia (por servir a quien sirve), mientras que su amo se encarga de arremeter contra la insensatez de la cordura con la desmesura de sus razones poéticas, erigiéndolas como la lanza que arma su irrefrenable afán caballeresco; instrumento que pese a verse reducido a astillas, persiste en sus lances de épico lirismo.

Para afianzar dicho postulado basta rememorar la resolución que el hidalgo manchego adopta tras su derrota frente al Caballero de la Blanca Luna: antes de ser definitivamente abatido por su recobrado juicio, don Quijote apela a convertirse en pastor a modo de 'consuelo' a la conclusión de sus días como caballero andante (II, 67: 1059-1064), y el motivo principal de su bucólica apetencia no es sino continuar rindiendo tributo a su inmarcesible amor: lo único que desea es que sus pensamientos y actos prosigan su derrotero hacia la loa a Dulcinea, pues cuando sus andanzas se veían favorecidas con alguna victoria (o cosa cercana a una), la forzosa e invariable declaración y encomienda a que siempre forzaba a los adversarios era la de encomiarla e ir a postrarse a sus pies para darle noticias de su fiel enamorado. Toda la travesía del Caballero de los Leones tuvo como objetivo medular enaltecer el nombre de Dulcinea.

Mas reparemos otro poco en la inclinación pastoril que manifiestan tanto el personaje como el autor. Es bastante llamativo el hecho siguiente:

Cervantes parodia con sarcasmo las novelas de caballerías, en cambio toma muy literalmente en serio el mundo garcilasiano-virgiliano del bu- 
colismo. [...] En el donoso y grande escrutinio que el cura y el barbero someten a la biblioteca de don Quijote, el cura argumenta que no deben ser quemados los libros pastoriles "porque no hacen ni harán el daño que los de caballerías han hecho; que son libros de entretenimiento, sin perjuicio de tercero". Y de uno de ellos, El pastor de Fílida decreta que debe guardarse como "joya preciosa" (Calvo: 30-31).

Así, tenemos que el respeto y la consideración que Cervantes sentía por la poesía eran mayúsculos; ${ }^{9}$ podemos afirmar que la tenía en tan alto concepto debido principalmente a la decisiva influencia ejercida por Garcilaso de la Vega. Tan sólo en el Quijote, además del explícito ejemplo ya citado, encontramos varios episodios de marcado linaje y formulación pastoril de raíz garcilasiana: la conversación con los cabreros y el famoso discurso utópico sobre la Edad de Oro (I, 11: 95-102), seguido inmediatamente del incidente de Grisóstomo y Marcela (I, 1214: 103-129). Y como un eco o subrayado de lo anterior, casi al final de la Primera parte (I, 50: 509-515) aparece otro cabrero ante la comitiva, quien junto con su cabra y la anécdota de Leandra la antojadiza (I, 51: 515-521) dan muestra de comportamiento arcádico, y qué decir de las dos zagalas, ya en la Segunda parte, que don Quijote llama "ninfas habitadoras destos prados y bosques", quienes afirman que se proponen representar dos églogas: "una del famoso poeta Garcilaso, y la otra del excelentísimo Camoes en su misma lengua portuguesa" (II, 58: 991). Y en fin, también hay huellas pastoriles — nada más para mencionar otro ejemplo de la Segunda parte, aunque sin duda podrían rastrearse más - en los capítulos que se ocupan de las bodas de Camacho el rico, Basilio el pobre y Quiteria (II, 19-21: 689-722).

Insistimos, esto es tan sólo en su obra capital. El resto de la producción cervantina está salpicada y en muchos casos enteramente dedica-

9 Además, el género caballeresco era en extremo susceptible a la parodia debido a las inconsistencias y francos absurdos que planteaba; atendamos a una puntualización de Riley al respecto: "La consideración independiente de sus lecturas puede explicarnos la preocupación de Cervantes por ciertos problemas. La torpeza e irresponsabilidad de muchos autores de libros de caballerías, y el contraste entre estas obras y el Orlando furioso, por ejemplo, pudo muy bien hacerle sentir curiosidad por los principios de la ficción literaria. Y desde luego, lo que parece influencia podría ser sólo una coincidencia casual, sobre todo cuando se trata de temperamentos similares en una misma época" (23). 
da a la cuestión bucólica. La devoción garcilasiana está presente desde un principio en el quehacer cervantino; la constante pastoril se halla prácticamente en la totalidad de la obra cervantina. Calvo acota muy acertadamente:

El eco del entusiasmo de Cervantes por la poesía de Garcilaso resuena desde la primera de sus obras, la "Elegía a la muerte de Isabel de Valóis", hasta la póstuma del Persiles [...] La Galatea reúne más que ninguna otra obra de Cervantes las citas y alusiones garcilasianas, comenzando por la más obvia y manifiesta: Galatea es el nombre de uno de los personajes de la Égloga $I$ [...] el personaje co-protagonista lleva el nombre Elicio, claro parónimo de Salicio [...] No es poco significativo, asimismo, que Cervantes denomine La Galatea como "égloga", a la manera de las composiciones de Garcilaso [...] hay un pasaje en que la Musa Calíope [...] hace una relación [...] de los excelsos poetas que unen la Antigüedad con el presente: La lista comienza con Homero, sigue con Virgilio, Enio, Catulo, Horacio, Petrarca, Dante, Ariosto, y tras éste, señala a Garcilaso (30).

La apuesta mayor de Cervantes no era la parodia caballeresca, génesis de la novela moderna tal como la conocemos; "Cervantes fue [...] un autor de marcada vocación pastoril. [...] se hubiera presentado a sí mismo no como el autor del Quijote sino como el autor de $L a G a$ latea" (30). Así lo hace en el autorretrato del prólogo de sus Novelas ejemplares: pondera y menciona en primer lugar a La Galatea y en segundo puesto coloca su obra cumbre. Es como si Cervantes se viera a sí mismo, sobre y ante todo, como un poeta pastoril: Beatus ille in locus amøenus.

\section{Injerencias más notables}

Garcilaso, admirado unánimemente por los lectores de los Siglos de Oro, era dechado de artista y de hombre: un individuo excepcional, un modelo, un paradigma. Cómo y qué fue Garcilaso para Cervantes y de qué modo entró en la obra literaria de éste son algunos de los temas de este ensayo. No es la primera vez ni será la última que se aborden: en el ám- 
bito de los estudios hispánicos son fundamentales. Lo que menos hace falta es valorar la poesía de Garcilaso o la obra cenital de Cervantes; pero quizá valga la pena buscar ángulos y rincones interesantes; si no nuevos, al menos estimulantes: suscitaciones para lecturas contemporáneas de los clásicos. Esperamos, si no hacer una contribución completamente original, sí por lo menos dar orden cierto a algunos materiales al alcance de todos los lectores interesados.

Al consultar la Enciclopedia cervantina de Juan Bautista AvalleArce (1997), en la entrada de Garcilaso de la Vega hallamos, además de otra constatación de que la influencia del toledano fue marcada y decisiva en prácticamente la totalidad de la obra de Cervantes, que dos versos en particular fueron muy citados por éste y encontraron hondo eco en sus textos. Avalle-Arce registra como única señal garcilasiana en la Primera parte del Quijote la cita 'directa' que se halla en la canción desesperada de Grisóstomo (I, 14: 120) del verso 606 de la Égloga II, "Echa con la doliente ánima fuera" — aunque Cervantes troca 'echa' por 'salgan'-, el cual es obviamente el primero de los dos recién aludidos y cuya presencia es recurrente en la obra cervantina. Se pueden rastrear alusiones, reelaboraciones, estilemas, citas o inserciones (como la anteriormente acotada) y guiños a este tópico; en La Galatea (III: 208), por ejemplo, hay "diversos recuerdos" del citado verso; asimismo, en el Persiles (II, IV: 179), Policarpa canta un soneto cuyo noveno verso calca el 606 de la Égloga II.

En segunda instancia nos topamos con los dos versos iniciales del celebérrimo Soneto $X$, “ $¡ O$ Oh dulces prendas por mi mal halladas, / dulces y alegres cuando Dios quería!”. La recitación de éstos por parte de don Quijote (II, 18: 680) es sólo la punta del iceberg; hallamos también " $¡ \mathrm{Oh}$, por mi bien, prenda hallada!" en Los baños de Argel (II, 143b [sic en la Enciclopedia...]); en el Persiles (I, IV: 67), Periandro exclama "oh, prenda, no sé si diga por mi bien o por mi mal hallada", y en la misma obra, más adelante (II, XV: 244) leemos “¡Oh únicas consoladoras de mi alma; ah ricas prendas por mi bien halladas, dulces y alegres en este y en otro cualquier tiempo!"; en La guarda cuidadosa (513a) advertimos en el parlamento de un soldado: "Ya que no lleva remedio de firme estas chinelas, que no fuera mucho, y más sobre tan 
dulces prendas, por mi mal halladas". ${ }^{10}$ Pero centrémonos por un momento en la aparición quijotesca de dichos versos e intentemos dilucidar sus implicaciones.

\section{Las tobosescas tinajas}

En el capítulo XVIII de la Segunda parte del Quijote, dedicado a la llegada y el aposentamiento de don Quijote y Sancho Panza en la casa del Caballero del Verde Gabán — es decir, don Diego Miranda—, el hidalgo manchego descubrió

muchas tinajas a la redonda, que, por ser del Toboso le renovaron las memorias de su encantada y transformada Dulcinea; y suspirando, y sin mirar lo que decía, ni delante de quién estaba, dijo:

${ }_{-}$Oh dulces prendas, por mi mal halladas, dulces y alegres cuando Dios quería!

¡Oh tobosecas tinajas, que me habéis traído a la memoria la dulce prenda de mi mayor amargura! (II, 18: 679-680).

El juego se plantea aquí con los dos versos del décimo soneto de Garcilaso de la Vega, recordado puntual y muy correctamente por don Quijote, sin deturpación ni deformación como la del verso "travestido" - así lo llama Antonio Armisén - por Altisidora en el capítulo LXX de la Segunda parte de la novela. Una nota de la edición del IV Centenario acerca de esas tinajas informa: "Cuya producción alfarera [la del Toboso] era abundante y muy estimada". Las tinajas tobosescas son vistas, pues - literalmente vistas, descubiertas con los ojos por el personaje-, como objetos admirables, cuyo valor no podía ignorar un hombre al tanto de las tareas agrícolas, como don Quijote.

Los célebres versos, como se sabe, glosan otros igualmente famosos de la Eneida: Dulces exuviae, dum fata deusque sinebat (Eneida, IV:

10 Ponderamos que estos dos versos garcilasianos son los más representativos, y asentadas quedan sus resonancias en Cervantes. No obstante, otro par corrieron igual suerte: nos referimos a “¡Oh más dura que el mármol a mis quejas!” (Égloga I, v. 57) y "Por estas asperezas se camina / de la inmortalidad al alto asiento / do nunca arriba quien de allí declina” (Elegía I, vv. 202-204). Cfr. Armisén 2010. 
651), que Miguel Antonio Caro, el gran filólogo y clasicista colombiano, traduce así, en sonora octava real que transcribimos completa (corresponde, según la numeración de Caro, a la estrofa CXXVII):

$¡ O h$ dulces prendas con mejor fortuna!

¡Dulces por siempre cuando Dios quería!

¡Mi espíritu os entrega, y mi importuna

Memoria cese con la vida mía!

La senda anduve que emprendí en la cuna.

Viví las horas que vivir debía:

Hoy, fin logrando a míseros afanes,

Van a otro mundo mis augustos manes [...].

Las prendas en la escena protagonizada por Dido son los arreos militares de Eneas; en el caso del soneto español no podemos saber con exactitud a qué se refiere la palabra "prendas", pero podemos suponerlo: un mechón de pelo de la amada, un anillo, unos pendientes, un collar - cualquier objeto entregado precisamente "en prenda" al galán para servir como memento amoroso-. El poema garcilasiano ha sido recreado en muchas ocasiones; la recreación o glosa cervantina en el Quijote es, acaso, una de las más sonrientes y divertidas.

Una vez registrada la señal garcilasiana, se abre el lugar para la reflexión y para algunos apuntamientos críticos. ¿Qué quiere decir esta resignificación —como la llamamos en el "apeíndice"- de un pasaje célebre de la poesía española? En boca de don Quijote, constituye un uso del canon poético garcilasiano para sus fines amorosos y sus tareas de caballero andante, tal como él las entiende a partir de sus insaciables lecturas de novelas de caballería: entre esas tareas deben figurar, por supuesto, las de evocar y homenajear a su "dama de pensamiento". En el marco de la narración cervantina, la inserción burlesca de versos admirados por Cervantes y prestados a su personaje para poner de relieve su locura, su impertinencia - esto es, la voluntad de jugar con valores establecidos sin herirlos ni intentar su destrucción, antes bien, poniéndolos en movimiento- - He aquí en plenitud el espíritu de la eutrapelia cervantina destacado por Francisco Márquez Villanueva: el entretenimiento - el Quijote es un libro de burlas - sin hiel, comedido, mesurado. 


\section{Conclusión}

La gravitación de la poesía de Garcilaso de la Vega en la obra de Miguel de Cervantes es innegable, en especial en el Quijote. Constituye un campo de estudio lleno de posibilidades, pero solamente si los investigadores van más allá del simple registro de "citas" o "glosas" garcilasianas y lo sitúan en una perspectiva amplia. Tal ha sido el espíritu que ha presidido la escritura de este ensayo, el cual asimismo se propuso avizorar, siempre con una apreciación crítica (y según sus respectivas pautas históricas), los accidentes y favores con que el canon influyó y fue influido por ambos autores. El estudio aquí emprendido tuvo por norte evidenciar los paralelismos y las afinidades entre Garcilaso y Cervantes, así como la influencia que tuvo la obra del poeta toledano en el alcalaíno, y el posterior eco que su literatura halló en las formas canónicas, erigiéndolos, con toda justicia, como los clásicos por antonomasia de la tradición literaria hispánica.

\section{Apeíndice}

* [Para simplificar la localización y confrontación de nuestros registros, ideamos el siguiente formato de referencia: divididas claramente de antemano ambas partes de la novela y "numeradas alfabéticamente" cada una de las señales garcilasianas, sin citar directamente la parte focalizada, ${ }^{11}$ establecemos: Capítulo o sección del Quijote, (página); Poema garcilasiano, verso o versos — v. o vv. - y (página en la citada edición de Bienvenido Morros).]

\section{Primera parte}

a) Último verso del soneto preliminar de "El Caballero del Febo a don Quijote de la Mancha” (p. 23); Égloga II, v. 1418 (p. 288).

11 Para la referencia completa y mucho mayor precisión véase la ed. de Francisco Rico del Quijote, del Instituto Cervantes, Madrid: Crítica, 1998. Las referencias a Garcilaso las manejamos ateniéndonos a la ed. de Bienvenido Morros, rehecha y abreviada de la Obra poética y textos en prosa, 2001 [cfr. bibliografía]. 
b) Cap. IV (p. 49); Égloga II, v. 653 (p. 254).

c) Cap. XI (p. 97; el discurso de la Edad de Oro); posible reminiscencia del verso 239 de la Égloga I (p. 210).

d) Canción de Antonio, Cap. XI (p. 100); Canción IV, vv. 90-91 (p. 156).

e) Canción de Grisóstomo, cap. XIV (p. 120); Égloga II, v. 606 (p. 252).

f) Cap. XX (p. 174); Canción III, vv. 1-2 (p. 146).

g) Cap. XXV (p. 238); Égloga II, vv. 602-627 (pp. 251-253).

h) Cap. XXV (p. 239); Soneto X, v. 2 (p. 96).

i) Versos compuestos por don Quijote, cap. XXVI (p. 251); Soneto I, v. 6 (p. 82).

j) Cap. XXX (p. 307); Soneto V, v. 13 (p. 89).

k) Cap. XXXIII (p. 335); mención de Luis Tansilo, amigo de Garcilaso, quien lo cita en su Soneto XXIV (v. 3; p. 118).

1) Soneto del Cap. XXXIV (p. 352); Sonetos $I$ y V, reelaboración completa y uso de tópicos y motivos (pp. 82 y 88-89, respectivamente).

m) En el discurso de las armas y las letras, Cap. XXXVIII (p. 397); "estilema garcilasesco" vida y cuidado reelaborado como "pensamientos y vida"; Sonetos I, v. 8, y III, v. 8 (pp. 82 y 84-85).

n) Cap. XLIII (p. 449); evocación del v. 1 del Soneto $V$, por medio de la frase "si yo no le trujera tan retratado en mi alma" (pp. 88).

n) Cap. XLVI (p. 475); Égloga I, vv. 202-204 (p. 212).

o) Cap. XLVIII (p. 494); La alusión a la comedia de Lope de Vega, La ingratitud vengada, título tomado de la oda "A la Flor de Gnido": "Hasta que finalmente / en duro mármol vuelta / y trasformada, / hizo de sí la gente / no tan maravillada / cuanto de aquella ingratitud vengada" (vv. 95-100, p. 158).

\section{Segunda parte}

a) Cap. III (p. 571); la frase "necesidad de comento", alusiva a las Anotaciones de Fernando de Herrera a la poesía de Garcilaso, también mencionadas en "El licenciado Vidriera".

b) Cap. IV (p. 580); acerca del poema de encargo al bachiller, evocación de la Canción V, encargada por Mario Galeota a Garcilaso. 
c) Cap. VI (p. 593); Elegía I, vv. 202-204 (p. 178).

d) Cap. VIII (p. 603); alusión a la Égloga III (y antonomásticamente a Garcilaso, a quien don Quijote llama "nuestro poeta").

e) Cap. X (p. 620); Égloga I, v. 81 (p. 203), y Égloga III, v. 17 (p. 310); "ánima mezquina", "de mi mal no harta".

f) Cap. XII (p. 635); vaga alusión al v. 10 del Soneto $V$ en el segundo verso del soneto del Caballero del Bosque.

g) Cap. XII (p. 636); Égloga II, vv. 95-97 (p. 226). (Esta señal garcilasiana fue comentada por Juan Bautista Avalle-Arce en su primer texto cervantino, para número 1 de la Nueva Revista de Filología Hispánica, en 1947).

h) Cap. XIII (p. 638); Soneto XI, vv. 7-8.

i) Cap. XIII (p. 640), "ninfa del verde bosque"; Égloga I, v. 805 (p. 261).

j) Cap. XVIII (p. 680); Soneto X, vv. 1-2 (p. 96); resignificación burlesca de dos de los versos más famosos del canon garcilasiano.

k) Cap. XX (p. 697); vaga alusión a la Égloga II, vv. 78-79 y 100 (también hay una posible alusión al poema de fray Luis de León compuesto "a la salida de la cárcel").

1) Cap. XXXII (p. 793); vaga alusión a la Elegía I, vv. 202-204, como en el cap. VI (véase II, c): "aspereza".

m) Cap. XXXII, (p. 798); Soneto V, v. 1 (p. 88); "vuestra grandeza... la viera en él toda retratada".

n) Cap. XXXV (p. 823); Soneto XIII, v. 12 (p. 101); uso peculiar, en Garcilaso, recogido por Cervantes, de la palabra "tamaño" como adjetivo.

n) Cap. XLVIII (p. 909); véase en el inciso $l$ de este apéndice la referencia al Soneto V; "la mayor hermosura... grabada y estampada en la mitad de mi corazón”. En esa misma página hay una alusión a la “ninfa del dorado tajo..." de la garcilasiana Égloga III (vv. 49 y ss.).

o) Cap. LVIII (p. 991); mención directa del parlamento de una de las zagalas de la "Arcadia fingida" del "famoso poeta Garcilaso y otra del excelentísimo Camoes".

p) Cap. LXI (p. 1018); Égloga III, vv. 63-64; descripción del locus amœenus durante el amanecer. 
q) Cap. LXIV (p. 1044); Soneto III, v. 1 (p. 84); acerca del mar, en un parlamento de Sancho Panza.

r) Cap. LXVII (p. 1061); Églogas I y II, passim; identificación tradicional de Juan Boscán con el pastor Nemoroso.

s) Cap. LXIX (p. 1071); Égloga III, una octava, vv. 9-16 (p. 309), segunda de las dos estancias que el mancebo canta en el Quijote.

t) Cap. LXX (p. 1078); Égloga I, v. 57 (p. 201); desde luego, Altisidora cambia el género: "duro" por "dura" pues se dirige a don Quijote (véase Armisén 2010).

u) Cap. LXX (p. 1081); mención de Garcilaso en el parlamento de don Quijote, que formula un reproche al mancebo por "hurtar" unos versos del poeta toledano.

v) Cap. LXXIV (p. 1099); recreación o rehechura de "las fórmulas con que solían comenzar los testamentos"; véase el principio del testamento de Garcilaso (p. 363).

\section{BIBLIOGRAFÍA}

Aladro-Font, Jorge y Ricardo Ramos Tremolada. "Ausencia y presencia de Garcilaso en el Quijote", en Cervantes: Bulletin of the Cervantes Society of America, 16: 2 (1996): 89-106. Artículo disponible en $<$ http://www.hnet.org/ cervant/csa/articf96/aladro.htm $>$ [fecha de consulta: 22 de junio de 2014].

Alonso, DÁmaso (ed.). La "Epistola moral a Fabio", de Andrés Fernández de Andrada [1978]. Madrid: Crítica, 1993.

ARMisÉN, ANTONIO. "Garcilaso y el verso travestido de Altisidora. Anaxárete, Dido, Avellaneda y la escritura meliorativa del Quijote de 1615", en Cervantes en el espejo del tiempo. María Carmen Marín Pina (coord.). Zaragoza: Prensas Universitarias de Zaragoza / Universidad de Alcalá de Henares, 2010: 15-60. Artículo disponible en $<$ https://www.academia. edu/3653311/Garcilaso_y_el_verso_travestido_de_Altisidora._Anaxarete_Dido_Avellaneda_y_la_escritura_meliorativa_del_Quijote_de_1615> [fecha de consulta: 7 de julio de 2014].

Avalle-Arce, Juan Bautista. Enciclopedia cervantina. México: Universidad de Guanajuato, 1997.

Azorín, "Garcilaso", en La poesía de Garcilaso: ensayos críticos. Elías L. Rivers (ed.). Barcelona: Ariel, 1974: 33-39. 
Blecua, José Manuel. "Garcilaso y Cervantes", en Homenaje a Cervantes. Madrid: Ínsula, 1947: 141-150. Artículo disponible en $<$ http://cvc.cervantes.es/literatura/quijote_antologia/blecua.htm $>$ [fecha de consulta: 8 de julio de 2014].

Calvo, Mariano. "Cervantes y Garcilaso: la voz a ti debida", en Revista Añil 26: 29-32. Artículo disponible en $<$ http://biblioteca2.uclm.es/biblioteca/ ceclm/ARTREVISTAS/a\%C3\%B1il/a\%C3\%B1il26/cervantes_calvo. pdf $>$ [fecha de consulta: 26 de junio de 2014].

Carreira, Antonio. "Góngora y el canon poético", en El canon poético en el siglo XVII. López Bueno (dir.). Sevilla: Universidad de Sevilla, 2010: 394-423.

CAStro, Américo. "El pensamiento de Cervantes" [1925], en Obra reunida, volumen uno. El pensamiento de Cervantes y otros estudios cervantinos. Madrid: Trotta, 2002.

Cervantes, Miguel De. Entremeses [1614]. Ed. Eugenio Asensio. Madrid: Castalia, 1970.

Cervantes, Miguel De. Viaje del Parnaso [1614]. Ed. Vicente Gaos, Madrid: Castalia, 1973.

Cervantes, Miguel de. Don Quijote de la Mancha [1605, 1615]. 2 vols. Ed. Francisco Rico. Barcelona: Crítica / Instituto Cervantes, 1998.

Cervantes, Miguel De. "La gran sultana", en Comedias II [1615]. Ed. Florencio Sevilla Arroyo. Madrid: Castalia, 2001: 323-457.

Cervantes, Miguel De. Don Quijote de la Mancha. Ed. Conmemorativa del IV Centenario. Madrid: Real Academia Española / Alfaguara, 2004.

Cervantes, Miguel De. Novelas ejemplares [1613]. Barcelona: Crítica, 2005.

Cervantes, Miguel De. La Galatea, Biblioteca virtual 2003. Texto disponible en $<$ http://biblioteca.org.ar/libros/656352.pdf $>$ [fecha de consulta: $16 \mathrm{de}$ julio de 2014].

Cervantes, Miguel de. Los trabajos de Persiles y Sigismunda. Texto preparado por Enrique Suárez Figaredo. Texto disponible en $<$ http://users.ipfw. edu/jehle/CERVANTE/othertxts/Suarez_Figaredo_Persiles.pdf $>$ [fecha de consulta: 16 de julio de 2014].

Cuevas Cervera, Francisco. "Cervantes en la configuración del canon de literatura española. Antologías y colecciones de literatura (1750-1850)", en Gramática, canon e historia literaria: estudios de Filología española entre 1750 y 1850. Victoriano Gaviño Rodríguez y Fernando Durán López (coords.). Madrid: Visor, 2010: 85-116.

Márquez Villanueva, Francisco. "La cultura del Cervantes pensador". Fundación Juan March. 22 de octubre de 1998. Conferencia disponible en $<$ http://www.march.es/conferencias/anteriores/voz.aspx?id=796> [fecha de consulta: 27 de junio de 2014]. 
Rico, Francisco (ed.). Mil años de Poesía Española, Antología comentada. Barcelona: Enciclopedias Planeta, 1996.

Riley, E. C. Teoría de la novela en Cervantes [1962]. Madrid: Taurus, 1995. Rivers, Elías (ed.). Poesía Lírica del Siglo de Oro. Madrid: Cátedra, 1997.

Vega, Garcilaso de La. Obras. Ed. Tomás Navarro. Madrid: Imprenta Clásicos Castellanos, 1911.

Vega, Garcilaso de La. Obra poética y textos en prosa. Ed. Bienvenido Morros Barcelona: Crítica, 1995.

Vega, Garcilaso de la. Obra poética y textos en prosa. Ed. Bienvenido Morros (rehechura y abreviación de la ed. de Biblioteca Clásica Crítica, 1995). Barcelona: Crítica, 2001.

Virgilio Maron, Publio. Eneida. Trad. y versif. castellana de Miguel Antonio Caro. Madrid: Librería de la Viuda de Hernando, 1890. Texto disponible en <http://cdigital.dgb.uanl.mx/la/1020014995_C/1020014995 T1/1020014995.PDF $>$ [fecha de consulta: 2 de julio de 2014]. 